\title{
Qualitative exploration of the effect of a television soap opera storyline on women with experience of postpartum psychosis
}

\author{
Lewis Roberts, Giles Berrisford, Jessica Heron, Lisa Jones, Ian Jones, Clare Dolman and Deirdre A. Lane
}

\section{Background}

Postpartum psychosis has recently been the focus of an in-depth storyline on a British television soap opera watched by millions of viewers.

\begin{abstract}
Aims
This research explored how the storyline and concomitant increase in public awareness of postpartum psychosis have been received by women who have recovered from the condition.
\end{abstract}

\section{Method}

Nine semistructured, one-to-one interviews were conducted with women who had experienced postpartum psychosis. Thematic analysis consistent with Braun and Clarke's six-step approach was used to generate themes from the data.

\section{Results}

Public exposure provided by the postpartum psychosis portrayal was deemed highly valuable, and its mixed reception encompassed potentially therapeutic benefits in addition to harms.

\section{Conclusions}

Public awareness of postpartum psychosis strongly affects women who have experienced postpartum psychosis. This research highlights the complexity of using television drama for public education and may enable mental health organisations to better focus future practices of raising postpartum psychosis awareness

\section{Declaration of interest}

$\mathrm{GB}$ is chair of action on Postpartum Psychosis. JH is director of action on Postpartum Psychosis. IJ is a trustee of action on Postpartum Psychosis and was a consultant to the BBC (television company) on the EastEnders storyline. CD is a trustee of action on Postpartum Psychosis, a trustee of BIPOLAR UK, vice chair of the Maternal Mental Health Alliance, and was a consultant to the BBC (television company) on the EastEnders storyline.

\section{Copyright and usage}

(c) The Royal College of Psychiatrists 2018. This is an Open Access article, distributed under the terms of the Creative Commons Attribution-NonCommercial-NoDerivatives licence (http://creativecommons.org/licenses/by-nc-nd/4.0/), which permits noncommercial re-use, distribution, and reproduction in any medium, provided the original work is unaltered and is properly cited. The written permission of Cambridge University Press must be obtained for commercial re-use or in order to create a derivative work.
Postpartum psychosis is a mental health crisis that occurs in up to 2 in every 1000 deliveries and accounts for $38 \%$ of maternal suicides in the UK. ${ }^{1,2}$ Also known as puerperal psychosis, the onset of this illness is typically within the first 2 weeks after childbirth. ${ }^{3}$ It is characterised by the sudden onset of symptoms, which include mania, confusion, depression, hallucinations and delusions. ${ }^{4}$ Although clinical recovery from this illness can take as little as 6-12 weeks, it often takes many years for mothers to feel fully recovered to their premorbid state. ${ }^{5}$ Understanding the experiences of those who suffer from postpartum psychosis is of the utmost importance if appropriate social and emotional support is to be offered to individuals following this event. To date, eight qualitative studies have investigated postpartum psychosis experiences. ${ }^{6-13}$ Recurring themes identified by this body of research include the strain this event puts on family relationships and frustration at the inadequacy of support offered by healthcare providers. ${ }^{10,13}$ However, understanding of the experiences of stigma and the effect that the potentially limited public awareness of postpartum psychosis has on this specific population remains limited.

\section{Television storyline}

Between January and March of 2016, the popular British television soap opera, EastEnders, aired a storyline where a character suffered from postpartum psychosis (see Table 1 for storyline synopsis). This storyline was proposed to the programme's script writers by representatives from the postpartum psychosis support charities Action on Postpartum Psychosis (APP) and Bipolar UK, in a bid to raise the public awareness of the condition. The average viewing audience per episode exceeded 7 million across the 50 episodes aired during this period, ${ }^{14}$ greater than the usual viewing figures of 6.7 million per episode. As postpartum psychosis is a condition that is generally not well understood by the public and has not had such a large-scale media exposure before, it is likely that public awareness of postpartum psychosis has increased considerably following this portrayal; APP saw its daily website visits double from 400 to 800 and received a 4 -fold increase in registrations for email peer support in the aftermath of the storyline. ${ }^{15}$

\section{Effect of media depictions of mental illness}

The societal effect of fictional media depictions of mental illness has been well documented. High-profile portrayals of suicide, for example, can cause negative outcomes, such as a rise in emulated suicide attempts, ${ }^{16,17}$ in addition to positive ones, such as raised awareness and an increase in health-seeking behaviour; internet searches for suicide prevention hotlines increased internationally following the release of the Netflix series ' 13 Reasons Why. ${ }^{18}$ Thus, the far-reaching influence of the media can help to drive the message about mental health nationally and globally. Less is known about how media portrayals of specific mental illnesses effect the populations they represent on a personal level. Cross-sectional studies have identified that those with lived experience of a portrayed illness often feel stigmatised and may alter their medication adherence, ${ }^{19,20}$ yet such phenomena have rarely been explored in-depth with qualitative methodology. 


\section{Table 1 EastEnders plot synopsis}

The central character of this storyline is Stacey, who becomes pregnant for the first time with her partner, Martin. Stacey received a diagnosis of bipolar disorder several years before her pregnancy. Shortly after giving birth to her son, Arthur, she begins experiencing her first symptoms of postpartum psychosis, which include hallucinations and delusions. Despite the concern of her family and friends, Stacey initially receives no healthcare input and her illness worsens, culminating in a climactic scene where she is poised on the roof of a tall building, leaving the viewer concerned for the well-being of both Stacey and her child. Shortly after this, Martin convinces Stacey to seek help at hospital, where she is sectioned against her will. After a long wait, Stacey is transferred from a general psychiatric hospital to a specialised mother and baby unit, before gradually being discharged home, making a good recovery from her illness.

\section{Potential impact of TV storyline of postpartum psychosis}

Establishing the reception of the EastEnders portrayal of postpartum psychosis may enable mental health organisations and television producers to better understand the effect of this method of raising awareness, and is necessary in tailoring appropriate support to women who have experienced postpartum psychosis. Additionally, this research may provide novel insight into recovered women's perceptions of the stigma surrounding severe maternal mental illness and the effect of increasing public knowledge of this condition.

\section{Aims and objectives}

The primary aim of this study is to explore how the EastEnders postpartum psychosis storyline and the concomitant increase in public awareness were received by women who have recovered from the condition. Specific secondary aims were (a) to understand how women who have recovered from postpartum psychosis feel their experiences relating to stigma have changed following this television portrayal, and (b) to understand how women who have recovered from postpartum psychosis feel the condition is perceived by the general public.

\section{Methods}

\section{Study design}

This qualitative study used inductive thematic analysis consistent with a critical realist epistemological framework. ${ }^{21}$

\section{Participants}

Purposive sampling of women who watched this EastEnders portrayal was facilitated by the UK-based charity APP. Run by a collaboration of experts by experience, healthcare professionals and academics, this charity offers support to over 1000 women with current or previous postpartum psychosis through means such as patient information, social media, peer support services and workshops. ${ }^{15}$ All 13 of the women who responded to the research advertisement on APP's online forum met the following inclusion criteria: (a) self-identified as having suffered and recovered from postpartum psychosis, (b) watched the EastEnders postpartum psychosis storyline, (c) were competent in the English language and (d) were able to provide written informed consent.

Women were excluded from participation if they had experienced an episode of postpartum psychosis within the previous 12 months to ensure that only women who had recovered from their psychotic episode were included in the study.

Of the 13 women who registered an initial interest, 9 responded positively to a formal postal study invitation and subsequently participated in an interview. Demographic and clinical information of the participants, collected upon interview completion, is shown in Table 2.

\section{Data collection}

Semistructured, one-to-one interviews were conducted and audiorecorded. Participants were offered the choice between a telephone interview $(n=8)$ or face-to-face interview at the APP office at the University of Birmingham $(n=1)$. Interviews were conducted during February and March of 2016, and lasted approximately 1 h, although duration varied between 43 and $97 \mathrm{~min}$.

The interview topic guide (see Table 3 ) was developed in conjunction with clinicians, APP staff and experts with lived experience of postpartum psychosis to address the research aims, using Laforest's Guide to Organising Semi-Structured Interviews with Key Informant as a template. ${ }^{22}$

\section{Ethics}

Ethical approval was granted by the Internal Research Ethics Committee at the University of Birmingham, UK. Informed verbal or written consent was obtained from each participant immediately before commencement of their interview. All procedures performed in studies involving human participants were in accordance with the ethical standards of Population Science and Humanities Research Ethics Committee at the University of Birmingham, UK, and with the 1964 Helsinki declaration and its later amendments or comparable ethical standards. Informed consent was obtained from all individual participants included in the study.

\section{Analysis}

Interview recordings were transcribed verbatim by the first author. Thematic analysis in accordance with Braun and Clarke's six-step approach was subsequently used with line-by-line open coding. ${ }^{23}$

\begin{tabular}{|c|c|c|c|c|c|c|}
\hline Participant No. & Interview Method & Age, Years & Ethnicity & Years Since First Episode & No. of Episodes & No. of Children \\
\hline P1 & Telephone & 61 & White British & 37 & 1 & 1 \\
\hline P2 & Telephone & 52 & White British & 23 & 2 & 2 \\
\hline P3 & Telephone & 36 & White British & 7 & 1 & 2 \\
\hline P4 & Telephone & 45 & White British & 21 & 1 & 1 \\
\hline P5 & Telephone & 28 & White British & 3 & 1 & 1 \\
\hline P6 & Telephone & 49 & White British & 10 & 1 & 2 \\
\hline P7 & Telephone & 65 & White British & 34 & 1 & 3 \\
\hline P8 & Face-to-face & 45 & White British & 10 & 1 & 1 \\
\hline P9 & Telephone & 30 & White British & 3 & 1 & 1 \\
\hline
\end{tabular}




\section{Key Questions}

1. Warm up questions: Ask about EastEnders viewing habits

2. How did watching the postpartum psychosis storyline make you feel?

3. Do you think this was an accurate portrayal of postpartum psychosis? Please can you explain why?

4. How do you think postpartum psychosis is viewed by the general population?

5. Questions on how experiences have changed
Further Questions

Generic Probing

Questions

Can you tell me more about that? Can you expand a little about that?

Can you give me some examples?

Why exactly do you feel that way?

n what ways was this portrayal similar to your experience of postpartum psychosis?

In what ways did this portrayal differ to your experience of postpartum psychosis?

Do you think the storyline could have been changed to make it more representative? If so, how?

What influence do you think this portrayal will have on public perceptions of postpartum psychosis?

In what ways has this portrayal been helpful/ unhelpful in raising awareness and educating the public about postpartum psychosis?

Why do you think this is the case?

What factors do you think influence the views the public hold towards it? Do you think postpartum psychosis is well-understood by the general public? What steps do you think could improve public understanding of the condition? What was your understanding of the condition before you suffered from it?

Do you feel like your likelihood of disclosing information about your experience of postpartum psychosis with other people has changed as a result of this media portrayal?

Do you feel as though you have been treated differently by others since the portrayal?

Have you noticed more people talking about the condition since its television portrayal?
Initial codes were systematically reviewed and collated into themes, which were refined as thematic categories, compared with each other and appraised against the raw data.

\section{Validity}

Methods highlighted by Guba and Lincoln to validate results were used at various stages in the analysis. ${ }^{24,25}$ Member validation, through asking participants to feedback on the preliminary themes via email, and deviant case analysis contributed to the refinement of the thematic categories. Analytic triangulation of the first transcript, between the first author and two other researchers, widened the breadth of subsequent coding, and themes were further revised following review and evaluation by the research team.

\section{Reflexivity}

To acknowledge and, to some degree, limit their unavoidable influence on the research findings, ${ }^{23}$ the first author, a 21-year old medical student with no first-hand experience of parenthood or psychosis, bracketed their preconceptions and, through the maintenance of a reflexive diary, considered how data collection and analysis may have been affected by their motivations, prior experiences and critical realist lens.

\section{Results}

The following five distinct themes were conceptualised and are presented with their respective constituent subthemes: public education, stigma, disclosure, reassurance and family relationships. Public education was identified as a superordinate theme because of its inseparable permeation of the theme's stigma and disclosure. See Figure 1 for a visual representation of thematic relationships.

\section{Public education}

\section{Hidden illness}

All nine women shared the view that before the broadcasting of the EastEnders storyline, the public understanding of postpartum psychosis was extremely limited. Often described as an 'unknown' or 'hidden illness', participants felt postpartum psychosis was a condition that the public were largely unaware of and commonly confused with postnatal depression. This perceived misunderstanding of postpartum psychosis extended beyond the general public and into the health profession. The knowledge of postpartum psychosis possessed by front-line medical staff was frequently described as 'inadequate', with multiple women recounting instances where their symptoms were misdiagnosed by healthcare professionals.

P4: I feel that people often think it's postnatal depression, and they don't understand it at all. It's taken me 20 years of really banging my head against the wall trying to make people aware of it.

P3: I mean healthcare professionals, the number I came across who had no idea what had happened, or when I said the words didn't know what it was.

\section{Perceived public influence of EastEnders}

The importance and perceived value of improving the public understanding of postpartum psychosis was ubiquitous across the dataset. The EastEnders storyline was credited with effectively raising the public awareness of the condition by most participants, with this success attributed to the following three reasons: the 'big audience' that EastEnders broadcasts to, the 'perfect storm' of parallel media coverage and the digestibility of soap opera storylines.

P2: I think the influence is brilliant because I think people will be much more aware of it because people have heard of puerperal psychosis.

P6: EastEnders is probably the best way, something like that is a really effective way of getting information across... With 


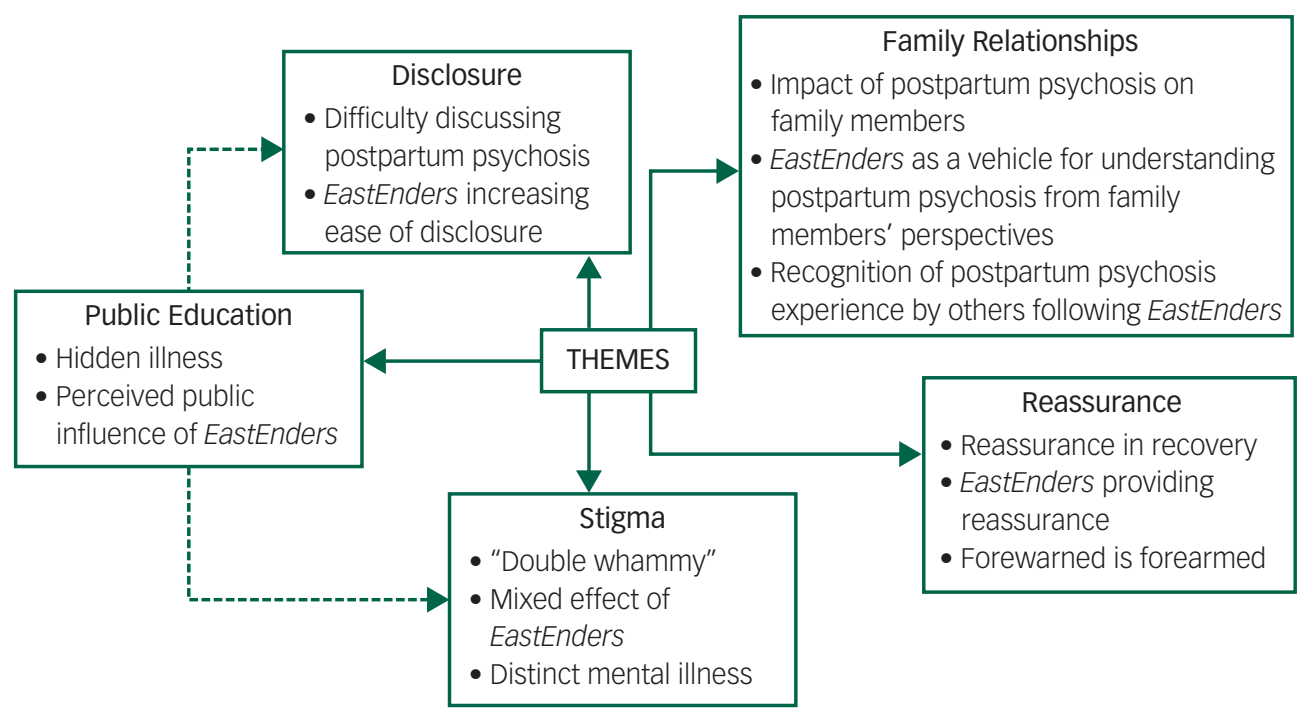

Fig. 1 Thematic map. This figure shows the relationship between the five thematic categories. The dashed arrows reflect the permeation of the theme public education into the themes disclosure and stigma.

EastEnders, there's loads of other storylines happening at the same time, and people take in that information without realising they are.

In addition to the desire to increase public awareness of postpartum psychosis, participants expressed a common set of key messages about postpartum psychosis that they felt should be communicated to the public. Some of these, such as the distinction between postpartum psychosis and postnatal depression, and that 'postpartum psychosis is something you recover from', were regarded to be effectively addressed by the EastEnders storyline.

However, some women described the television portrayal as a 'wasted opportunity' because of its failure to disseminate information about postpartum psychosis that holds personal significance. This information, regarded with high importance and repeatedly emphasised across the data-set, was that postpartum psychosis can happen 'out of the blue' and that 'it can happen to anyone'. The television character's history of bipolar disorder before the onset of their postpartum psychosis was frequently cited as the primary barrier to the delivery of these messages.

P7: I don't think it any way has enhanced the alarming fact that for quite a lot of women, postpartum psychosis is totally out of the blue... that it is something which you can be absolutely, totally unprepared for.

Such high-profile media exposure of postpartum psychosis was regarded as responsible for influencing the public's attitude towards the illness. Potential limitations and negative consequences of using the format of a television soap to educate the public about postpartum psychosis were highlighted by several participants. Most notably, portraying a single case of postpartum psychosis was perceived to fail at representing the variety of individual experiences.

P6: If you think that most people's knowledge of postpartum psychosis will be based on EastEnders, they will only have that one instance to think of as an example of it, so it's 'oh well it wouldn't happen to me or my daughter, or my granddaughter, because we're not bipolar', so in fact it's a little bit dangerous to do that.

\section{Stigma}

'Double whammy'

A prominent phenomenon recurring through all the interviews was the perception of, and experiences relating to stigma. The importance of overcoming the perceived stigma surrounding postpartum psychosis was equally apparent. Although largely connected with the perception of a 'deep-rooted' general mental illness stigma, three participants explicitly described how they felt the depth of the stigma surrounding postpartum psychosis pervaded beyond this because of the postnatal timing of the illness. Unmet personal and societal expectations placed on early motherhood compounded the negative feelings engendered by the general mental illness stigma to create a 'double-whammy' effect.

P3: I think it's one of the worst stigmas around mental illness because it's supposed to be this really wonderful, happy time with your perfect beautiful baby.

P8: It's a double whammy. Not only the stigma of being mentally ill, you've got the stigma of being a mentally ill mother, a bad mum. All pregnant women, all new mums think about 'am I a good mum?' and it's a really big thing anyway, but then to bring on mental illness as well, it's massively so.

\section{Mixed effect of EastEnders}

Expectations for the EastEnders portrayal to sensationalise postpartum psychosis were largely unmet because of the 'realistic' storyline that reflected specific, yet limited aspects of each participant's individual experience. However, the perceived effect of the portrayal on the stigma surrounding postpartum psychosis was varied. Although two women commented on the storyline as specifically 'stigma-busting', four participants felt that it would exacerbate the existing stigma surrounding postpartum psychosis. Reasons to support this view all related to the choice of character, who had a history of bipolar disorder before suffering from postpartum psychosis.

P1: ... if they'd picked another character, perhaps someone who wasn't already mentally ill and had other mental health issues and someone who wasn't dealing with a big secret like the child's fatherhood, I would have felt happier because it's easier for people to say 'oh yeah, that's [character], she's the resident person with mental health in that programme'. 


\section{Distinct mental illness}

Although the majority of participants did not find the bipolar storyline stigmatising, only one of the nine women self-identified as having bipolar disorder. Women who were treated in a general psychiatric hospital often gave a narrative of feeling separate and distinct from other inpatients. This distinction was, in part, attributed to their perception of the distinct time-limited nature of postpartum psychosis, as well as its postnatal timing. Furthermore, the distinction between postpartum psychosis and other postnatal illnesses, such as postnatal depression, was also emphasised.

P1: I still think that people would see postpartum psychosis like schizophrenia, like bipolar. They wouldn't see it as a, well I've got my own views, but they wouldn't see it as a reactive, a reaction to pregnancy and childbirth like us, a psychiatric emergency because of childbirth.

\section{Disclosure}

\section{Difficulty discussing postpartum psychosis}

There was a large variation between the degrees to which participants had openly shared their experience of postpartum psychosis with other people. Although sharing their experience was described as a beneficial and cathartic process, nearly all participants reported feeling a reluctance, fear or difficulty in disclosing their experience at some point during their recovery from postpartum psychosis. This was attributed to a perception that 'outsiders' cannot comprehend the experience of postpartum psychosis, stigma surrounding the illness, the perception that discussing it makes others feel 'uncomfortable' and the long-lasting effect of previous 'deleterious' disclosure experiences.

Despite this reluctance to disclose to others, many women simultaneously expressed a desire and perceived duty to share their experience. The possession of these incongruous thoughts led to three participants feeling guilt and shame at hiding their experience of postpartum psychosis.

P7: ... it's very useful to be able to sort of put your experiences in perspective by talking about them and telling people about them. P1: It's awful I know, I feel ashamed to say it because I work in mental health and I should be saying 'I've had [postpartum psychosis]' or shouting it from the rooftops, and yet I can't.

\section{EastEnders increasing ease of disclosure}

The ability to openly disclose was unanimously regarded as important. Six participants described how this soap opera storyline had increased their likelihood of disclosing and discussing their experience of postpartum psychosis to some degree. The perceived increased ease of disclosure following this storyline was attributed to the following reasons: increased self-confidence, relevance and topicality of postpartum psychosis, EastEnders providing a 'safe arena' to discuss postpartum psychosis and improved understanding of postpartum psychosis by those who have seen the portrayal.

P5: Yeah I think it has changed because I think if I was now to tell somebody within my family or friends that didn't know I had postpartum psychosis, it would be easier to say 'oh I had postpartum psychosis, it was similar to what [character] from EastEnders had'. So I wouldn't have to go into all the details of what the illness actually is, because they'd be aware of what it is really.

The influence of this storyline on disclosure was not expressed by all participants, with three women stating that it had not affected their likelihood of sharing their experience with others. Reasons given were that 'family and friends aren't that much EastEnders watchers' and that 'friends that I want to know my story already know it'.

\section{Reassurance}

\section{Reassurance in recovery}

A deep desire for reassurance recurred throughout participants' narratives of recovery. Women described a need to be assured that they were not alone in experiencing postpartum psychosis, seeking to find stories of other people who had shared this experience.

All seven women who had met peers with experience of postpartum psychosis (primarily through the charity APP) emphasised the significance of this meeting. Describing it as 'magical' and 'a real kind of light-bulb moment', women referred to this coming together as pivotal in their pursuit of reassurance. However, the difficulty in meeting fellow sufferers was commonly expressed, with two participants waiting over 30 years to meet a fellow sufferer.

P8: I desperately wanted to see a normal person, who was just like me and had it and got better. I just needed to know that I wasn't an alien or a monster, that it wasn't just me, that it happens to everyday women.

P4: I didn't actually meet anybody who had had postpartum psychosis until 13 years after I had it, and then at that time it changed a lot because talking to that group of women made such a massive difference to how I talked about it and how I felt about it. I felt much more comfortable then about being open about it.

\section{EastEnders providing reassurance}

One participant, who had not met a peer with postpartum psychosis experience, recounted how watching the EastEnders storyline had, to some degree, fulfilled her need to be reassured. Although no other women explicitly expressed this degree of reassurance from watching this soap opera, they all identified with aspects of the portrayal, which was reported to 'resonate really strongly'.

P2: I was sitting there thinking 'my goodness, that was just like me'... but that kind of helped, to see somebody going through the same as what I went through.

However, just as identifying with the storyline had the potential to reassure, aspects of the storyline that reflected individuals' experiences were often described as 'upsetting' and 'painful' to watch. Furthermore, discrepancies between the storyline and personal experiences of postpartum psychosis were found by some participants to be frustrating and disengaging.

P4: I found that one bit was really distressing for me was when [character] first went into the general psychiatric ward, and she was separated from her baby, and I found that that was really upsetting and that really brought it all back to me.

P8: I've lost interest now because it's so different from what I've experienced.

\section{Forewarned is forearmed}

Described as a 'frightening' and 'horrific' experience, participants reported feeling 'totally unprepared' for their psychotic episode, with none of the women having any prior awareness of the illness. Being aware of postpartum psychosis before childbirth was perceived to be important by all nine women, who felt that possession of this knowledge would have helped address the fear and distress they experienced as a result of not understanding what was wrong during their psychosis. The modality of a soap opera storyline was seen to have some merit in achieving this increase in awareness. 
P2: If I'd known about it I'd probably have, I'm not saying it would have stopped it, but it probably would have helped to understand a little thinking 'this is what I'm having', because obviously if you've never heard of anything and you go off your rocker, you think 'my God, what is wrong?'

\section{Family relationships}

\section{Effect of postpartum psychosis on family members}

All participants discussed the, largely negative, effect that their postpartum psychosis episode had on their immediate family members, particularly their partner. This included short-term effects such as distress and trauma, as well as long-term consequences; most notably, the illness' influence on the couple's decision to have subsequent children, with two participants describing the significant damage inflicted on spousal relationships by their episode.

P9: I suppose the main thing, well it's made my partner, I don't think he wants to have any more children because of it ... I think it's certainly made us think twice about it because I'm sure that if I hadn't had been unwell then we would definitely have another child, so yeah it has really impacted.

EastEnders as a vehicle for understanding postpartum psychosis from family members' perspectives

Although both immediate and long-lasting implications of postpartum psychosis on family members were recognised by participants, many women acknowledged that their understanding of their family's experience during the time of their psychosis was limited. This was often ascribed to having a poor memory of events surrounding their psychotic episode and a lack of open discussion about the experience.

P2: ... I didn't think his side of it, and he actually admitted to me how frightened he was for me. I had no idea he was even the slightest bit concerned about me at the time.

Some women found that their understanding of family members' experiences during this period improved as a result of watching this soap opera. The storyline acted as a vehicle through which they were able to revisit their own psychotic experience from the perspective of others.

P9: I think what was really useful for me, was to get some insight into what my family and what my partner would have been going through... I think it certainly made me have more empathy for my family and my partner.

Five women reported watching the storyline alongside a close family member, usually their partner. This was felt to be beneficial, deepening mutual understanding of each other's experiences, as a result of discussion driven by the programme. Providing a 'new angle' to reflect on their experiences was deemed important because of the limited postpartum psychosis discussion participants reported having before the television storyline.

P2: ... we hardly talked about it and he [husband] actually came around and said a few things to me and I thought 'God, you never mentioned that to me before', and we've been married 29 years now.

\section{Recognition of postpartum psychosis experience by others following} EastEnders

Compared with partners and immediate family members, distant relatives and friends were perceived to have a much weaker grasp of the gravity of the postpartum psychosis experience. However, many participants observed receiving an improved appreciation of this experience from others after this television storyline was aired.
P5: I think it's helped her [sister-in-law] understand what postpartum psychosis was and what it's sort of like for me. Because back then it wasn't in the media or anything like that, none of my family even knew what was going on... So I think it helped my family members to sort of understand a bit more of why I was like that and what sort of triggered it.

\section{Discussion}

Limited public awareness of postpartum psychosis was found to be a key issue for, and strongly affected these women, even decades after their clinical recovery, driving stigma and acting as a barrier to disclosure. The perceived value of increasing public exposure of postpartum psychosis was unanimously shared, and this storyline was generally well-received because of its perceived effect on this. Positive features of the portrayal included its incorporation of key stigma-busting messages and its large viewing audience, which enabled participants to disclose their experience more openly with others. Nonetheless, EastEnders' potential to promote misconceptions, drive stigma and cause distress was of concern. Portraying a single case of postpartum psychosis was seen to be insufficient at capturing the variety of individual experiences. Possible therapeutic benefits of watching the storyline were also reported, such as normalising postpartum psychosis experiences and driving positive discussion between family members. The generated themes demonstrate the capacity of the EastEnders storyline to affect women with experience of postpartum psychosis, both directly, on a personal level, and indirectly, through perceived societal effects.

The large variation within the data-set perhaps reflects the individuality of television storyline interpretation. ${ }^{26}$ The reception to the storyline, and the individual and societal platforms through which its effects were mediated, are coherent with Pirkis et al.'s review of mental illness media portrayals. ${ }^{19}$ Although this review found such media to only perpetuate existing stigma, participants in our study perceived the EastEnders storyline to have both beneficial and harmful consequences. This discrepancy may be explained by the participants' strong desire for an increase in the public exposure of postpartum psychosis, and the collaboration between the script writers and postpartum psychosis experts in the production of the storyline. Value in the latter process could consequently demonstrate a potential benefit achievable through mental health organisations working in conjunction with television producers. Where this is not possible, producers could follow the steps outlined by O'Brien et al. to deliver a socially responsible portrayal, which include adhering to international safe messaging guidelines and providing viewers with sources of information and support. ${ }^{27}$

Despite its novel focus on the phenomenon of a television portrayal of postpartum psychosis, many of this study's findings build on dimensions of the existing body of research on recovery from this illness. The discovery that culturally derived expectations of maternal roles compound the negative feelings induced by general mental illness stigma is congruent with research conducted by Robertson and Lyons. ${ }^{12}$ Furthermore, detrimental short-term and long-term implications of the psychotic episode on women's partners, identified in this study, are consistent with the well-documented effect postpartum psychosis has on significant others and nuclear family members. ${ }^{10,12,13}$ However, the overall positive effect postpartum psychosis had on relationships in the long-term, as reported by Wyatt et al., was not apparent in this data-set. ${ }^{13}$

The EastEnders storyline had positive effects on participants' personal lives. It normalised postpartum psychosis experiences through reassuring individuals that they are not alone and prompted a shared understanding of events between family members, a process that has been proposed to aid recovery. ${ }^{13}$ These possible benefits suggest that engaging with a personal narrative of postpartum 
psychosis, through media such as a fictional soap opera storyline, can improve the well-being of women recovering from this illness. Art forms such as film have long been used in psychotherapy, ${ }^{28}$ and therapeutic merits of this practice mirror those identified by this research. These include providing hope for individuals through reassuring them that they are not alone in their experience, ${ }^{29}$ and prompting discussion between family members resistant to discussing the central issue. ${ }^{30}$

Although voluntarily watching a drama storyline on television is undoubtedly distinct from being prescribed film as part of psychological treatment, the parallel between both processes and reported benefits arguably warrants enquiry tailored to investigating the use of such media in the postclinical recovery from postpartum psychosis. The ubiquity of television and film access ${ }^{31}$ and the under-use of psychological therapies in this condition ${ }^{13}$ provide a strong argument for such investigation.

Interestingly, despite its potential therapeutic merit, participants' reflections on the storyline largely focused on its perceived population influence rather than the personal effect of watching the portrayal. This further exemplifies the significance to recovered women of increasing public awareness of postpartum psychosis. However, perceptions of the storyline's effect on the public should not be examined in isolation of Davison's third-person effect. ${ }^{32}$ Praise and concerns expressed by participants about the influence of the EastEnders portrayal on the public perceptions of postpartum psychosis may be ungrounded because of the tendency of individuals to overestimate the influence of mass media messages on other people. ${ }^{32}$ Notwithstanding this, irrespective of whether such impressions are well founded, possession of these viewpoints will continue to affect the individuals who carry them.

Outlining the significance, effect and consequences of increasing the public awareness and understanding of postpartum psychosis on recovered women could help inform mental health organisations of the necessity and wider benefit of educating the public about this illness, encouraging organisations both domestically and overseas to raise the public profile of the condition. Ascertainment of key postpartum psychosis messages expressed by women with past experience of the condition, and the factors perceived to influence how this is received by the public, may help shape such future media campaigns. Further investigation into this population's priorities for disseminating public messages about postpartum psychosis could be undertaken.

\section{Limitations}

Because of the sensitive nature of the research topic, recruitment methods were chosen to maximise acceptability to participants. Through recruiting self-selecting members who use a postpartum psychosis support charity and voluntarily engaged with the EastEnders storyline, this study favoured the voices of women with an integrative recovery style over those who recover through 'sealing over', avoiding investigation into their past experience. . $^{11,33,34}$ Although qualitative research does not seek statistical generalisability, ${ }^{35}$ these potential systematic differences between the study sample and the overall postpartum psychosis population may limit the theoretical application of research findings, with integrative recovery associated with higher social competence and better long-term outcomes. ${ }^{33}$ Future work in this field could therefore recruit through National Health Service registers and purposively sample for younger women who are less actively engaged with recovery support.

The widened perspective of research findings, provided by the significant heterogeneity in age and time since first postpartum psychosis episode between participants, offers novel insight previously unexplored by other recent qualitative research in this population, which rarely seeks the perspective of women 20 years or further into their recovery from postpartum psychosis. ${ }^{9-13}$ However, important and distinct experiences may be elicited by interviewing a more narrowly focused age range or those with more recent experience of postpartum psychosis.

Because of time constraints placed on data collection, the study sample size was not driven by data saturation. However, a retrospective saturation analysis, similar to the evaluation carried out by Guest, ${ }^{36}$ was conducted with the aim of determining the extent of data saturation reached. Only 2 of the 102 individual codes were uniquely raised during the final interview. Although this denotes that absolute data saturation was not achieved before this point, the fact that $98 \%$ of useful data was produced after eight interviews demonstrates a level of homogeneity within the data-set, indicating that further enquiry may have been fruitless.

In conclusion, public awareness of postpartum psychosis, or at least the perception of this by women with experience of the illness, appears to significantly effect recovery experiences in this population. The public exposure provided by the television portrayal of postpartum psychosis was deemed important, whereas its varied reception highlights the complexity of using this medium in public education. Potentially therapeutic benefits of watching the portrayal were also identified. This work may enable mental health organisations to better focus future public education practices and tailor support to recovering women. Additionally, it highlights the potential for future investigation into the use of this media form in the recovery from postpartum psychosis.

Lewis Roberts, BMedSC, The Medical School, University of Birmingham, UK; Giles Berrisford, MBChB MSC FRCPsych, Birmingham and Solihull Mental Health NHS Foundation Trust, Barberry National Centre for Mental Health, UK; Jessica Heron, PhD, Institute of Clinical Sciences, University of Birmingham, Barberry National Centre for Mental Health, UK; Lisa Jones, PhD, Department of Psychological Medicine, University of Worcester, UK; Ian Jones, MRCPsych, PhD, Institute of Psychological Medicine and Clinical Neurosciences, Cardiff University, UK; Clare Dolman, BSC, Section of Women's Mental Health, Institute of Psychiatry, Psychology and Neuroscience, King's College, London, UK; Deirdre A. Lane, PhD, University of Birmingham Institute of Cardiovascular Sciences, City Hospital, Birmingham, UK

Correspondence: Deidre Lane, PhD, University of Birmingham Institute of

Cardiovascular Sciences, City Hospital, Dudley Road, Birmingham B187QH. deirdrelane@ nhs.net

First received 5 Sep 2017, final revision 5 Jan 2018, accepted 29 Jan 2018

\section{Acknowledgements}

We thank the nine study participants for their invaluable contribution to this project. In addition, we acknowledge Lucy Milton and Erin Timmins for their administrative support, and Dr Antje Lindenmeyer for advising on qualitative methodology. We also thank Andrea Lambert and Val Rapson for providing participant input into the design of the study protocols and topic guide.

\section{References}

1 Centre for Maternal and Child Enquiries (CMACE). Saving Mothers' Lives: reviewing maternal deaths to make motherhood safer: 2006-08. The Eighth Report on Confidential Enquiries into Maternal Deaths in the United Kingdom. Br J Obstet Gynaecol 2011; 118(suppl 1): 1-203.

2 Kendell RE, Chalmers JC, Platz C. Epidemiology of puerperal psychoses. $\mathrm{Br} \mathrm{J}$ Psychiatry 1987; 150: 662-73.

3 Jones I, Chandra PS, Dazzan P, Howard LM. Bipolar disorder, affective psychosis, and schizophrenia in pregnancy and the post-partum period. Lancet 2014; 384: 1789-99.

4 Di Florio A, Smith S, Jones I. Postpartum psychosis. The Obstetrician and Gynaecologist 2013; 15: 145-50.

5 Berrisford G, Lambert A, Heron J. Understanding postpartum psychosis. Community Pract 2015; 88: 22.

6 Doucet S, Letourneau N, Blackmore E. Support needs of mothers who experience postpartum psychosis and their partners. J Obstet Gynecol Neonatal Nurs 2012; 41: 236-45. 
7 Edwards E, Timmons S. A qualitative study of stigma among women suffering postnatal illness. J Ment Health 2005; 14: 471-81.

8 Engqvist I, Nilsson K. Experiences of the first days of postpartum psychosis: an interview study with women and next of kin in Sweden. Issues Ment Health Nurs 2013; 34: 82-9.

9 Glover L, Jomeen J, Urquhart T, Martin C. Puerperal psychosis - a qualitative study of women's experiences. J Reprod Infant Psychol 2014; 32: 254-69.

10 Heron J, Gilbert N, Dolman C, Shah S, Beare I, Dearden S, et al. Information and support needs during recovery from postpartum psychosis. Arch Womens Ment Health 2012; 15: 155-65.

11 McGrath L, Peters S, Wieck A, Wittkowski A. The process of recovery in women who experienced psychosis following childbirth. BMC Psychiatry 2013; 13: 341

12 Robertson E, Lyons A. Living with puerperal psychosis: a qualitative analysis Psychol Psychother 2003; 76: 411-31.

13 Wyatt C, Murray C, Davies J, Jomeen J. Postpartum psychosis and relationships: their mutual influence from the perspective of women and significant others. $J$ Reprod Infant Psychol 2015; 33: 426-42.

14 Broadcasters Audience Research Board. Weekly Top 30 Programmes. BARB 2016 (http://www.barb.co.uk/viewing-data/weekly-top-30/).

15 Action on Postpartum Psychosis. About Us. The UK Postpartum Psychosis Network, 2016 (http://www.app-network.org/about-us/)

16 Phillips D. The werther effect. Sciences 1985; 25: 32-40.

17 Hawton K, Simkin S, Deeks J, O'Connor S, Keen A, Altman D, et al. Effects of a drug overdose in a television drama on presentations to hospital for self-poisoning: time series and questionnaire study. BMJ 1999; 318: 972-7.

18 Ayers J, Althouse B, Leas E, Dredze M, Allem J. Internet searches for suicide following the release of 13 reasons why. JAMA Intern Med 2017; 177: 1527-9.

19 Pirkis J, Blood R, Francis C, McCallum K. On-screen portrayals of mental illness: extent, nature, and impacts. J Health Commun 2006; 11: 523-41.

20 Stuart H. Media portrayal of mental illness and its treatments. CNS Drugs 2006 20: 99-106.

21 Bhaskar R. A Realist Theory of Science. Taylor \& Francis, 2008.
22 Laforest J. Guide to Organising Semi-Structured Interviews with Key Informant. Institut national de santé publique, 2009 (http://www.crpspc.qc.ca/ Guide_entretien_versionWEB_eng.pdf).

23 Braun V, Clarke V. Using thematic analysis in psychology. Qual Res Psychol 2006; 3: 77-101.

24 Guba E, Lincoln Y. Effective Evaluation: Improving the Usefulness of Evaluation Results Through Responsive and Naturalistic Approaches. Jossey-Bass, 1981.

25 Lincoln Y, Guba E. Naturalistic Inquiry. Sage, 1985.

26 Livingstone S. Television and the active audience. In Formations: A 21st Century Media Studies Textbook (ed D Fleming): 175-199. Manchester University Press, 2000.

27 O'Brien K, Knight J, Harris S. A call for social responsibility and suicide risk screening, prevention, and early intervention following the release of the netflix series 13 reasons why. JAMA Intern Med 2017; 177: 1418-9.

28 Berg-Cross L, Jennings $P$, Baruch R. Cinematherapy: theory and application. Psychother Priv Pract 1990; 8: 135-56.

29 Ballard M. The family life cycle and critical transitions: utilizing cinematherapy to facilitate understanding and increase communication. J Creativity Ment Health 2012; 7: 141-52.

30 Dermer S, Hutchings J. Utilizing movies in family therapy: applications for individuals, couples, and families. Am J Fam Ther 2000; 28: 163-80.

31 Sharp C, Smith J, Cole A. Cinematherapy: metaphorically promoting therapeutic change. Couns Psychol Q 2002; 15: 269-76.

32 Davison W. The third-person effect in communication. Public Opin Q 1983; 47: 1.

33 Modestin J, Soult J, Malti T. Correlates of coping styles in psychotic illness. Psychopathology 2004; 37: 175-80.

34 McGlashan T. Recovery style from mental illness and long-term outcome. J Nerv Ment Dis 1987: 175: 681-5.

35 Green J. Qualitative methods. Community Eye Health 1999; 12: 46-7.

36 Guest G. How many interviews are enough?: an experiment with data saturation and variability. Field Methods 2006; 18: 59-82. 